\title{
La scène en contrechamp. Anecdotes françaises et traditions de jeu au siècle des Lumières, textes édités par Sabine Chaouche
}

\section{Marisa Ferrarini}

\section{(2) OpenEdition \\ Journals}

Edizione digitale

URL: http://journals.openedition.org/studifrancesi/27592

DOI: $10.4000 /$ studifrancesi.27592

ISSN: 2421-5856

\section{Editore}

Rosenberg \& Sellier

\section{Edizione cartacea}

Data di pubblicazione: 31 décembre 2006

Paginazione: 604

ISSN: 0039-2944

\section{Notizia bibliografica digitale}

Marisa Ferrarini, «La scène en contrechamp. Anecdotes françaises et traditions de jeu au siècle des Lumières, textes édités par Sabine Chaouche », Studi Francesi [Online], 150 (L | III) | 2006, online dal 30 novembre 2015, consultato il 08 novembre 2020. URL : http://journals.openedition.org/studifrancesi/ 27592 ; DOI : https://doi.org/10.4000/studifrancesi.27592

Questo documento è stato generato automaticamente il 8 novembre 2020.

\section{cc) $($ ) $\ominus$}

Studi Francesi è distribuita con Licenza Creative Commons Attribuzione - Non commerciale - Non opere derivate 4.0 Internazionale. 


\title{
La scène en contrechamp. Anecdotes françaises et traditions de jeu au siècle des Lumières, textes édités par Sabine Chaouche
}

\author{
Marisa Ferrarini
}

\section{NOTIZIA}

La scène en contrechamp. Anecdotes françaises et traditions de jeu au siècle des Lumières, textes édités par Sabine CHAOUCHE, Paris, Honoré Champion, 2005, pp. 157.

1 Applicando al teatro la tecnica del «campo-controcampo», tipica del linguaggio cinematografico, la curiosa antologia curata da Sabine Chaouche ha il merito di introdurci appieno nella vita teatrale del Settecento, con i suoi livori e le sue simpatie, $i$ suoi osanna e i suoi sberleffi: al punto di vista del personaggio sulla scena si contrappone quello dello spettatore che diventa egli stesso attore, misconoscendo o amplificando gli intenti dell'autore. Ritrovando le sue radici di piazza, il teatro è da intendersi come spettacolo globale. Gli aneddoti raccolti non solo lo confermano, ma permettono di relativizzare le teorie sull'arte teatrale e di confrontare, in modo ludico, regole e pratiche sceniche. Da qui la scelta di proporre in appendice l'Essai sur la tradition théâtrale di Cailhava de l'Estandoux (Paris, Charles-Pougens, imprimeur libraire, 16 Germinal, an VI [1798], pp. 139-144). Anche Cailhava, a fine secolo, rileva come le tradizioni teatrali siano rimesse in causa, come le contraddizioni, gli eccessi della recitazione conducano a snaturare il teatro di Molière. Se l'attore vuol farsi davvero valere, deve attenersi al testo e non recitare in palcoscenico la propria commedia. È giunta l'ora di una teatralità ragionata, senza commistioni tra chi recita $\mathrm{e}$ un pubblico beota che tenta di assurgere a ruolo di protagonista. 
2 La stessa esigenza di razionalità emerge dagli aneddoti estrapolati dalle Observations sur l'art du comédien di D'Hannetaire (seconda edizione del 1774) e dalle Anecdotes dramatiques di Laporte e Clément (1775), materiale su cui è costruito il presente lavoro. Nel Settecento, precisa l'A., non esiste un'opera specifica consacrata alle «curiosités théâtrales» (perché di curiosità e amenità si tratta), come invece avverrà nell'Ottocento. Particolare curioso, insolito, raccolto a fine moralistico o ricreativo, intorno ad un personaggio o ad un evento, l'aneddoto si nasconde ovunque (memorie, epistolari, trattati o romanzi); esce nel bel mezzo della lettura come da una scatola a sorpresa, effervescente e gaio, rifugiandosi dopo il suo numero dietro le quinte per fissarsi nella memoria. In assenza di poetica e di storia dell'aneddoto drammatico, S. Chaouche tenta un approccio al contempo estetico e poetico. Presenta gli aneddoti in ordine cronologico di pubblicazione, optando dunque per la loro eterogeneità e lasciando al lettore la possibilità di spaziare in base alla propria fantasia. Ma puntualmente fornisce un percorso tematico, vuoi per le note con gioco di rimandi o il repertorio degli aneddoti in appendice (pp. 145-146). 